\title{
Influence of temperature and sliding speed on the subsurface microstructure evolution of EN AW-6060 under sticking friction conditions
}

Cite as: AIP Conference Proceedings 1896, 140012 (2017); https://doi.org/10.1063/1.5008168 Published Online: 16 October 2017

Vidal Sanabria, and Soeren Mueller

\section{ARTICLES YOU MAY BE INTERESTED IN}

Tribological investigations of the applicability of surface functionalization for dry extrusion processes

AIP Conference Proceedings 1896, 140001 (2017); https://doi.org/10.1063/1.5008157

Modification of the anisotropy and strength differential effect of extruded AZ31 by extrusionshear

AIP Conference Proceedings 1960, 030008 (2018); https://doi.org/10.1063/1.5034851

Backward rod extrusion of bimetallic aluminum-copper alloys at room temperature AIP Conference Proceedings 2113, 030001 (2019); https://doi.org/10.1063/1.5112529
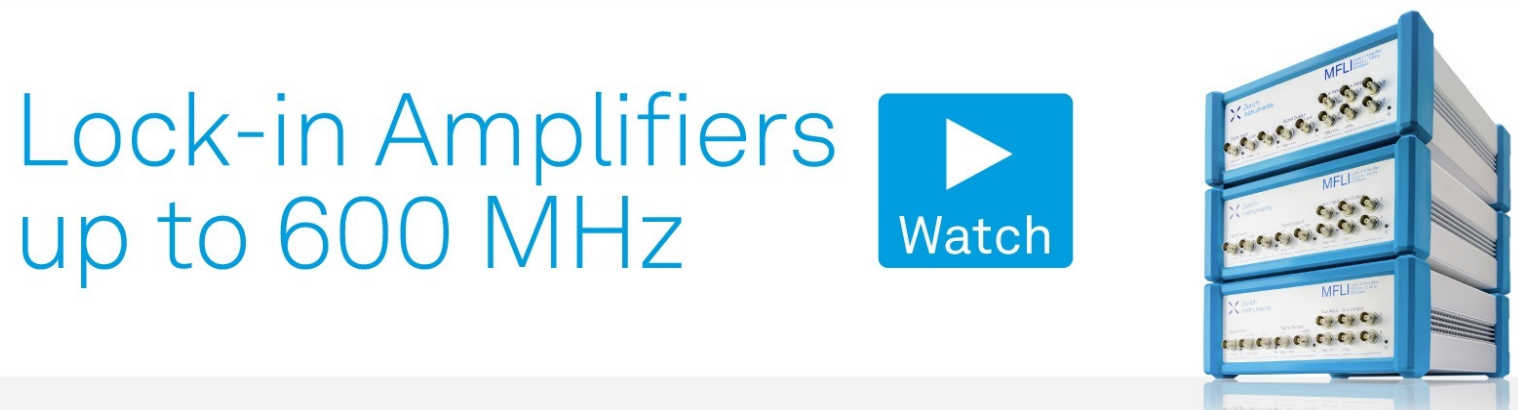


\title{
Influence of Temperature and Sliding Speed on the Subsurface Microstructure Evolution of EN AW-6060 under Sticking Friction Conditions
}

\author{
Vidal Sanabria ${ }^{1, a)}$ and Soeren Mueller ${ }^{1, b)}$ \\ ${ }^{1}$ Extrusion Research and Development Center, Technische Universität Berlin, Gustav-Meyer-Allee 25, 13355, \\ Germany
}

a)Corresponding author: vidal.sanabria@fzs-berlin.de

b)soeren.mueller@tu-berlin.de

\begin{abstract}
The microstructure evolution of the friction boundary layer of the aluminum alloy EN AW-6060 was investigated. Sticking friction tests at different temperatures and sliding speeds were carried out. A severe deformation below the friction surface was observed by means of LOM and EBSD mapping. Thus, the thickness variation and the grain structure of the high deformation zone could be described. Fibrous structure was observed at $300{ }^{\circ} \mathrm{C}$ and $400{ }^{\circ} \mathrm{C}$, while equiaxed grains with high misorientation angle $\left(>15^{\circ}\right)$ were generated at higher temperatures. Additionally, abnormal grain growth and coarse grains were detected at high sliding speeds $(10 \mathrm{~mm} / \mathrm{s}, 42 \mathrm{~mm} / \mathrm{s})$ at $450{ }^{\circ} \mathrm{C}$ and $500{ }^{\circ} \mathrm{C}$ respectively.
\end{abstract}

\section{INTRODUCTION}

Extruded products exhibit a microstructure gradient through the cross section due to heterogeneous deformation history. According to the literature, the grain structure of the extruded profile can be unrecrystallized fibrous, fully recrystallized and mixture of the two [1]. In general, a fibrous structure is desired because it increases the strength of the product. Contrary, recrystallized coarse grains are avoided since they reduce the machinability, fatigue and stress corrosion resistance. Recrystallized large grains at the profile surface, also called peripheral coarse grain (PCG), are responsible for bending failure, streaking and poor decorative finish [2].

It is widely accepted that a recrystallized surface layer is highly influenced by the ram speed, extrusion ratio, billet temperature as well as the alloying elements [3]. Moreover, experimental investigations of 6xxx aluminum alloys have showed more details about the PCG formation [4]. Thus, when the extrudate leaves the die its peripheral microstructure is characterized by fine equiaxed grains with high misorientation angle $\left(>15^{\circ}\right)$. This structure is caused due to the high local strain $(\varepsilon>3)$ and dynamic recrystallization. After few seconds the energy still stored in the microstructure can promote an abnormal grain growth.

A close relationship between the extrusion parameters and the evolution of the surface microstructure can be achieved [1,5]. However, the combination of dissimilar strain rates and temperatures at the shear zone and bearing land hinder the investigation of their single influence on the microstructure evolution.

Shear deformation conditions similar to the extrusion process can be reproduced applying the new axial friction test [6]. In the present work, this method is used to investigate the influence of temperature and sliding speed on the microstructure evolution of the friction boundary layer of aluminum alloy EN AW-6060. Special attention is paid to the thickness and the grain structure of the high shear deformation zone, which is analyzed by means of LOM and EBSD techniques. 


\section{EXPERIMENTAL PROCEDURE}

Sticking friction experiments were carried out applying the new axial friction test developed at the Extrusion Research and Development Center of the Technische Universität Berlin. As workpiece small billets with diameter $7.8 \mathrm{~mm}$ and length $10.5 \mathrm{~mm}$ were used, which were extracted from cast and homogenized billets of aluminum alloy EN AW-6060. In each test a billet was placed inside an unused hollow cylinder (H13, 48 HRc) as shown in Fig. 1a. The friction pair was heated for 15 min applying an electric furnace. Two punches pressed the billet with a constant axial force $(80 \mathrm{~N})$ during the heating phase, while internal thermocouples allowed to measure the billet temperature. After the preset temperature was reached, the punches set up the block inside the hollow cylinder with a constant strain rate of $0.0005 \mathrm{~s}^{-1}$. The compression force $\left(F_{a}\right)$ needed to generate sticking conditions between the block and hollow cylinder depends on the block temperature $\left(12825 \mathrm{~N}\right.$ at $300{ }^{\circ} \mathrm{C}, 3395 \mathrm{~N}$ at $400{ }^{\circ} \mathrm{C}, 2400 \mathrm{~N}$ at $450{ }^{\circ} \mathrm{C}$ and $1765 \mathrm{~N}$ at $500{ }^{\circ} \mathrm{C}$ ) as reported in a previous work [7]. Subsequently, the axial force is kept constant and the hollow cylinder is moved down $3.5 \mathrm{~mm}$ with a constant speed $(0.1 \mathrm{~mm} / \mathrm{s}, 1 \mathrm{~mm} / \mathrm{s}, 10 \mathrm{~mm} / \mathrm{s}$ and $42 \mathrm{~mm} / \mathrm{s})$. Afterwards, the system was released and the block and hollow cylinder were quenched together in water within $60 \mathrm{~s}$ approximately. The billet microstructure was later analyzed by means of LOM and EBSD techniques.

Similar experiments were carried out in the past [8], however different parameters such as: hydrostatic condition and procedure of specimen separation were applied. In the former campaign the axial compression force was calculated to generate a normalized normal stress $\left(\sigma_{\mathrm{n}}{ }^{\prime}\right)$ of 1.5 . However, in the present experiments this value was increased $\left(\sigma_{\mathrm{n}}{ }^{\prime}=3.5\right)$ to achieve full sticking [7]. Additionally, in former experiments each specimen was separated from the hollow cylinder before quenching. Due to the strong adhesion of the aluminum alloy to the steel H13 at high temperatures, additional plastic deformation in the bottom side of the friction boundary layer was detected (Fig. 1b). This negative effect was avoided in the present trial since the friction pair was carefully separated after quenching. Figures 1.c,d,e show the friction sub-layer and the improved high shear deformation zones of specimens tested at $42 \mathrm{~mm} / \mathrm{s}$ and $300{ }^{\circ} \mathrm{C}, 400{ }^{\circ} \mathrm{C}$ and $500{ }^{\circ} \mathrm{C}$ respectively. A detailed description of the axial friction test is reported in [6].

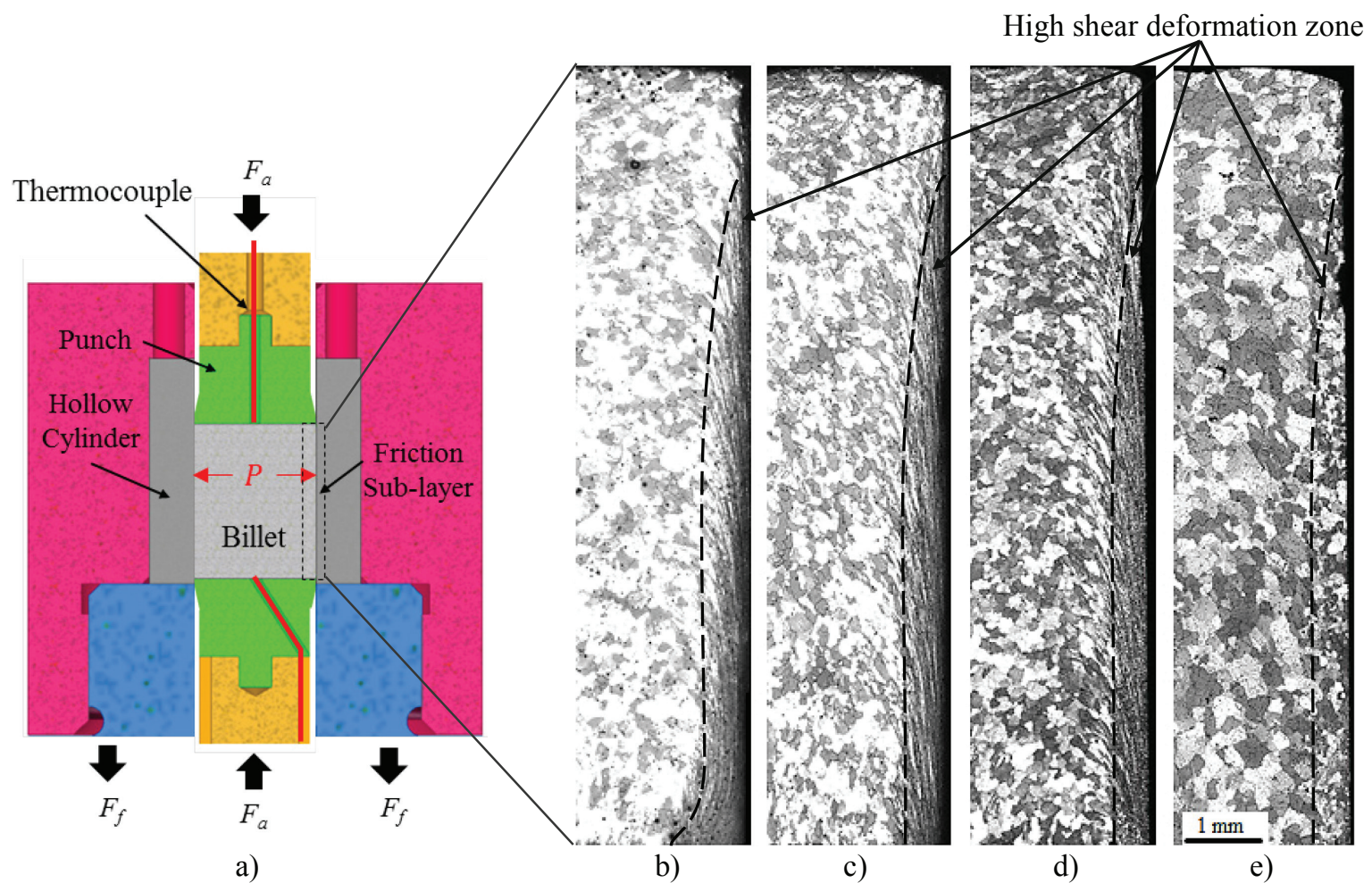

FIGURE 1. Microstructure analysis after sticking friction test. a) Schematic representation of the axial friction test, b) friction sub-layer of specimens subjected to $42 \mathrm{~mm} / \mathrm{s}$ and b) $300^{\circ} \mathrm{C}$ (old method), and c, d, e) at $300{ }^{\circ} \mathrm{C}, 400{ }^{\circ} \mathrm{C}$ and $500{ }^{\circ} \mathrm{C}$ respectively (improved method) 


\section{RESULTS AND DISCUSSION}

As it was also observed in a previous work [8], the top side of the friction sub-layer suffered a lower strain than the rest of the friction boundary layer (Fig. 1.b,c,d,e). Therefore the high shear deformation zone was not produced along the whole specimen. For that reason, the microstructure analysis was carried out only in the middle zones of the samples.

When sticking friction takes place it is assumed that a relative movement between the block surface and the hollow cylinder is not possible. Under this condition, a relative displacement between both objects occurs when the surface sub-layer of the softer material (EN WA-6060) is plastically deformed. Due to the tangential nature of the force, the material below the friction surface suffers a severe shear deformation. Figure 2a shows the friction boundary layer of aluminum alloy EN AW-6060 subjected to a sliding speed of $0.1 \mathrm{~mm} / \mathrm{s}$ at $300{ }^{\circ} \mathrm{C}$. The shear deformation zone is placed at the friction periphery, followed by original dendritic grains toward the center of the specimen. The micrograph confirms the localized high strain under the friction surface characterized by a fibrous grain structure. An additional analysis carried out by means of EBSD mapping revealed more details of this area. A zone of low and high grain fragmentation is observed, and identified in Fig. $2 \mathrm{~b}$ as low and high deformation zones respectively. From the microstructure it can be deduced that the highest strain and thus strain rate occurs at the surface and decreases radially towards the center of the sample $[9,10,11]$.
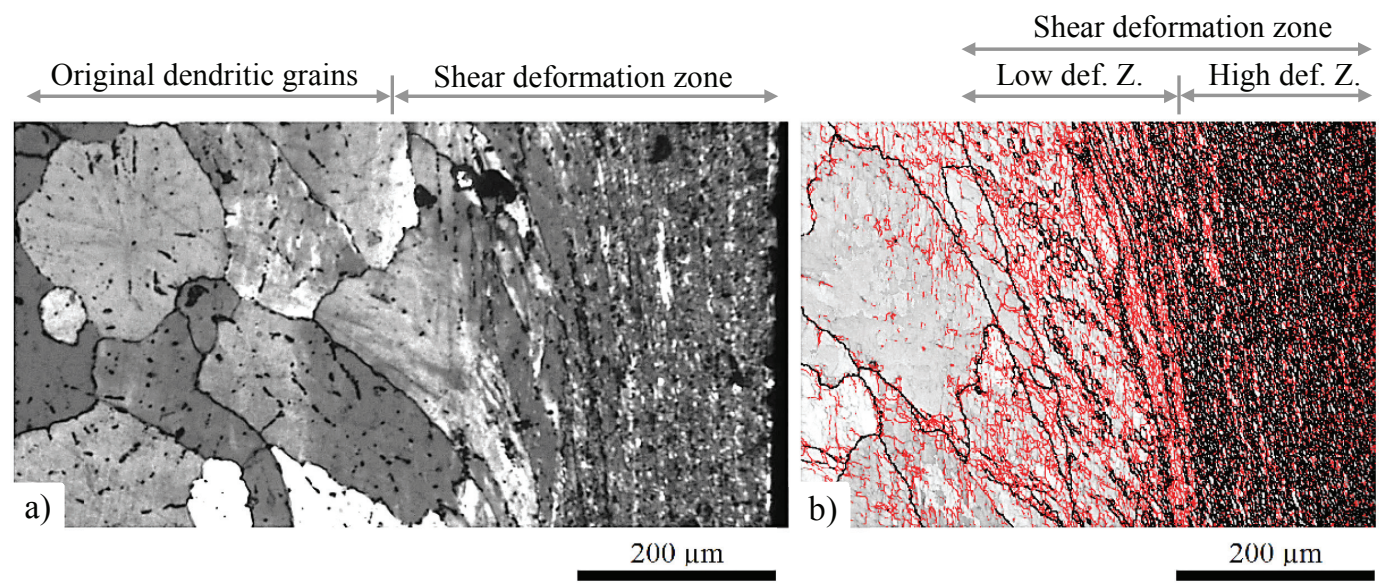

FIGURE 2. Friction boundary layer of a specimen tested at $300^{\circ} \mathrm{C}$ and $0.1 \mathrm{~mm} / \mathrm{s}$ analyzed by means of a) LOM and b) EBSD map (HAGB $>15^{\circ}$ in black, $\mathrm{LABGs}<5^{\circ}$ in red)

Figure 3 compiles selected micrographs of the friction boundary layer taken from samples tested at $300{ }^{\circ} \mathrm{C}, 400{ }^{\circ} \mathrm{C}$, $450{ }^{\circ} \mathrm{C}$ and $500{ }^{\circ} \mathrm{C}$ as well as at the different sliding speeds $0.1 \mathrm{~mm} / \mathrm{s}, 1 \mathrm{~mm} / \mathrm{s}, 10 \mathrm{~mm} / \mathrm{s}$ and $42 \mathrm{~mm} / \mathrm{s}$. In all cases, the original dendritic grains as well as the shear deformation zones could be recognized. Thus, the influence of the temperature and the sliding friction speed on the thickness and microstructure of the shear deformation zone could be analyzed.

At $300{ }^{\circ} \mathrm{C}$ (Fig. 3a,e,i,m) and $400{ }^{\circ} \mathrm{C}$ (Fig. 3b,f,j,n) a fibrous grain structure was observed in the shear deformation zone as shown in Fig. 2a. The main macroscopic difference between these samples is the thickness of the high deformation zone, which increases at higher sliding speeds and lower temperatures. According to the literature, during plastic deformation of metals with high stacking fault energy such as aluminum alloys two dynamic processes take place at the same time. On the one hand, strain hardening is generated due to the interaction and multiplication of dislocations. On the other hand, dynamic recovery (DRV) occurs mainly caused by means of annihilation of dislocations [12]. At $300{ }^{\circ} \mathrm{C}$ and under the particular conditions of strain rate present in these tests, the effect of the strain hardening overcame the DRV. Hence, at a higher speed the subsurface is subjected to a higher strain rate leading to a local hardening. Since the subsurface is strengthened, more adjacent softer material is forced to shear during the friction stroke, increasing thus the thickness of the shear zone. The dominant effect of the strain hardening was also confirmed at $300{ }^{\circ} \mathrm{C}$ with the evolution of the friction stress and the micro hardness mapping of the same samples published in a previous work [7]. On the other hand, the lower thickness variation at $400{ }^{\circ} \mathrm{C}$ was due to a more effective DRV at higher temperatures. 


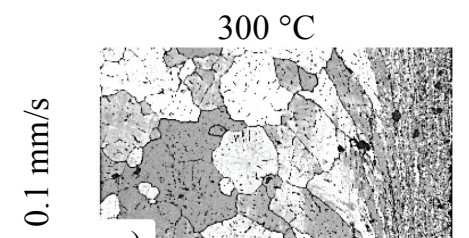

a) $f(x+2)$,
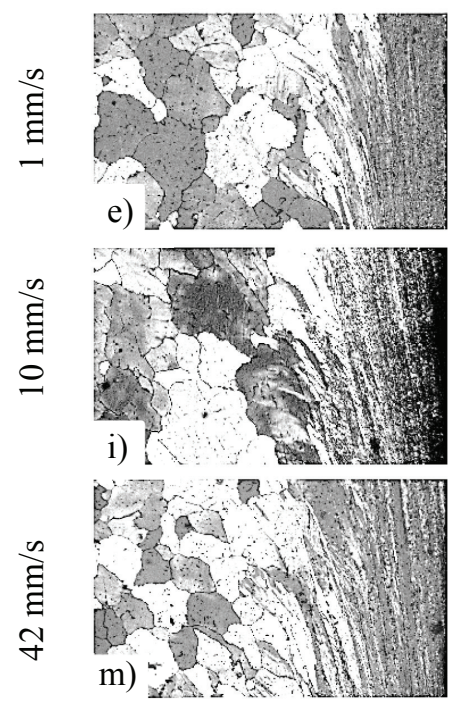
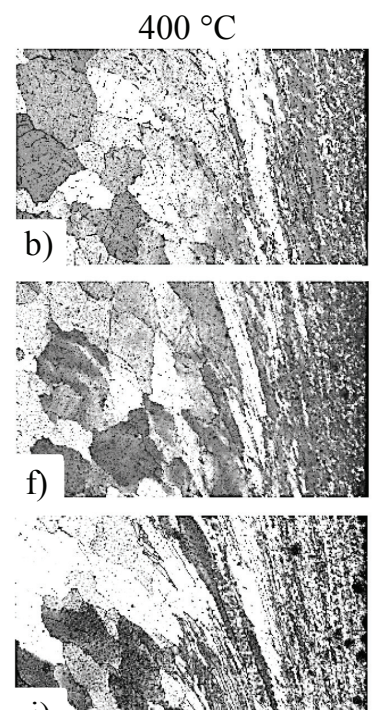

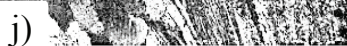

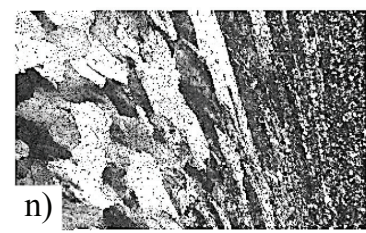

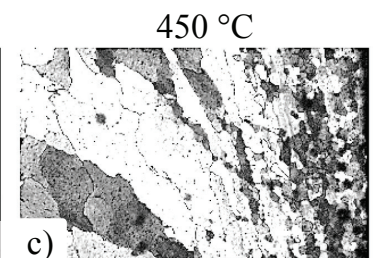
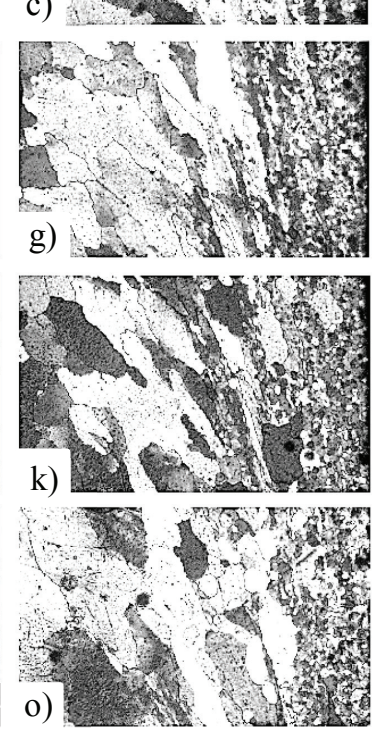
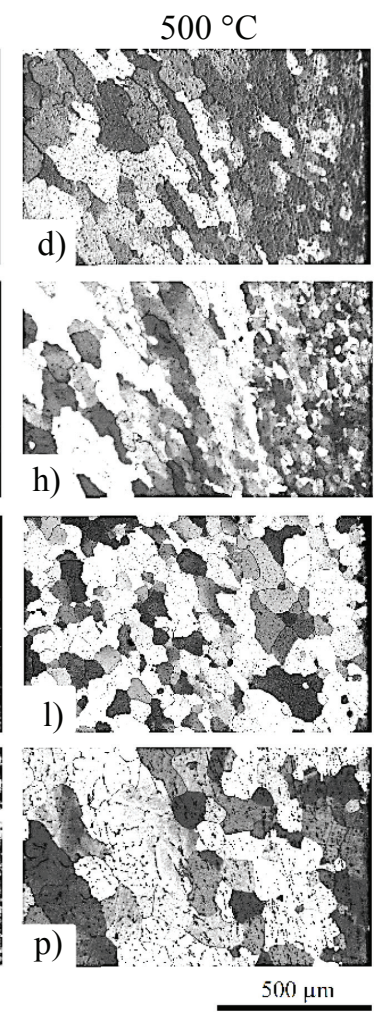

FIGURE 3. Evolution of the friction boundary layer of aluminum alloy EN AW-6060 at different temperatures $\left(300{ }^{\circ} \mathrm{C}\right.$, $400{ }^{\circ} \mathrm{C}, 450{ }^{\circ} \mathrm{C}$ and $500{ }^{\circ} \mathrm{C}$ ) and at a sliding speed of a,b,c,d) $\left.\left.0.1 \mathrm{~mm} / \mathrm{s}, \mathrm{e}, \mathrm{f}, \mathrm{g}, \mathrm{h}\right) 1 \mathrm{~mm} / \mathrm{s}, \mathrm{i}, \mathrm{j}, \mathrm{k}, \mathrm{l}\right) 10 \mathrm{~mm} / \mathrm{s}$ and $\mathrm{m}, \mathrm{n}, \mathrm{o}, \mathrm{p}$ ) $42 \mathrm{~mm} / \mathrm{s}$.

Micrographs of samples tested at $450{ }^{\circ} \mathrm{C}$ and $500{ }^{\circ} \mathrm{C}$ are shown in Fig. 3c,g,k,o and Fig. 3d,h,l,p respectively. The results showed a thicker shear deformation zone than at $300^{\circ} \mathrm{C}$ and $400{ }^{\circ} \mathrm{C}$. Lower flow stress at higher temperatures allowed a greater deformation area toward the center of the sample. Therefore at $450{ }^{\circ} \mathrm{C}$ and $500{ }^{\circ} \mathrm{C}$ is expected a lower strain and strain rate in the high deformation zone than at $300{ }^{\circ} \mathrm{C}$ and $350{ }^{\circ} \mathrm{C}$. In general, slightly elongated grains could be observed in the low deformation zone, while small equiaxed grains were present in the high deformation zone. Severe deformation of aluminum alloys at high temperature generates small equiaxed grains by means of geometric dynamic recrystallization gDRX [10,13,14], also called grain dividing gDRV [15]. Small equiaxed grains can be formed at $300^{\circ} \mathrm{C}$ and $400^{\circ} \mathrm{C}$ as reported in [10]. However duo to their small grain size, they could not be observed by means of LOM. At $450^{\circ} \mathrm{C}$ and $500^{\circ} \mathrm{C}$ a large number of dislocations is annihilated reducing the effect of strain hardening and facilitating a more efficient DRV process. At high temperatures a more rapid annihilation occurs and the steady-state balance is achieved at a larger subgrain size [16]. Thus, the efficient annihilation and the higher grain boundary mobility at higher temperatures could explain the larger equiaxed grain size at high temperatures.

Single coarse grains surrounded by small equiaxed grains were present in the high deformation zone at $400{ }^{\circ} \mathrm{C}$ and $10 \mathrm{~mm} / \mathrm{s}$ and $42 \mathrm{~mm} / \mathrm{s}$ (Fig. 3k,o). This particular bimodal grain size was generated possibly by the abnormal grain growth during the $60 \mathrm{~s}$ before quenching. The literature reports that the amount of high- and low-angle boundaries generated during the hot deformation influences the abnormal grain growth process [17]. In addition, microstructural studies of extruded aluminum alloys suggest the influence of the grain texture and the temperature on the static recrystallization. Experimental extrusion trials demonstrated that a temperature reduction from $520{ }^{\circ} \mathrm{C}$ to $480{ }^{\circ} \mathrm{C}$ increased the stored strain energy and promoted preferential grain growth of recrystallized cube grains [18].

At $500{ }^{\circ} \mathrm{C}$ two different grain structures were detected in the high deformation zone. Small equiaxed grains were observed in samples tested at $0.1 \mathrm{~mm} / \mathrm{s}$ (Fig. 3d) and $1 \mathrm{~mm} / \mathrm{s}$ (Fig. 3h). Moreover, coarse grains were generated at $10 \mathrm{~mm} / \mathrm{s}$ (Fig. 31) and $42 \mathrm{~mm} / \mathrm{s}$ (Fig. 3p). The higher sliding speed $(10 \mathrm{~mm} / \mathrm{s}$ and $42 \mathrm{~mm} / \mathrm{s})$ and therefore, higher strain rate in the severe deformation zone produced the stored strain energy needed to propitiate a normal static 
recrystallization, grain growth or a combination of both processes. Microstructure results observed at $500{ }^{\circ} \mathrm{C}$ reveals that not only the temperature but also the dynamic deformation characteristics have a relevant influence on the subsequent static restoration mechanisms. Texture analysis of the microstructure has to be done to investigate the particular causes of this static phenomena.

The thickness evolution of the high deformation zone at different temperatures and friction speeds was summarized in Fig. 4. Increasing the sliding speed from $0.1 \mathrm{~mm} / \mathrm{s}$ to $42 \mathrm{~mm} / \mathrm{s}$ at $300{ }^{\circ} \mathrm{C}$ the thickness grew around $70 \%$. However, for the same speed variation the thickness increased only $20 \%, 28 \%$ and $30 \%$ at $400{ }^{\circ} \mathrm{C}, 450{ }^{\circ} \mathrm{C}$ and $500{ }^{\circ} \mathrm{C}$ respectively. Thus, the sliding speed had a greater influence on the thickness at $300{ }^{\circ} \mathrm{C}$ possibly due to the strong effect of the strain hardening. Moreover, this effect was reduced at higher temperatures because of the more efficient dynamic recovery. The possible influence of the static restoration on the thickness variation at high temperatures $\left(450{ }^{\circ} \mathrm{C}, 500{ }^{\circ} \mathrm{C}\right)$ and high sliding speed $(42 \mathrm{~mm} / \mathrm{s})$ can be also observed in the Fig. 4.

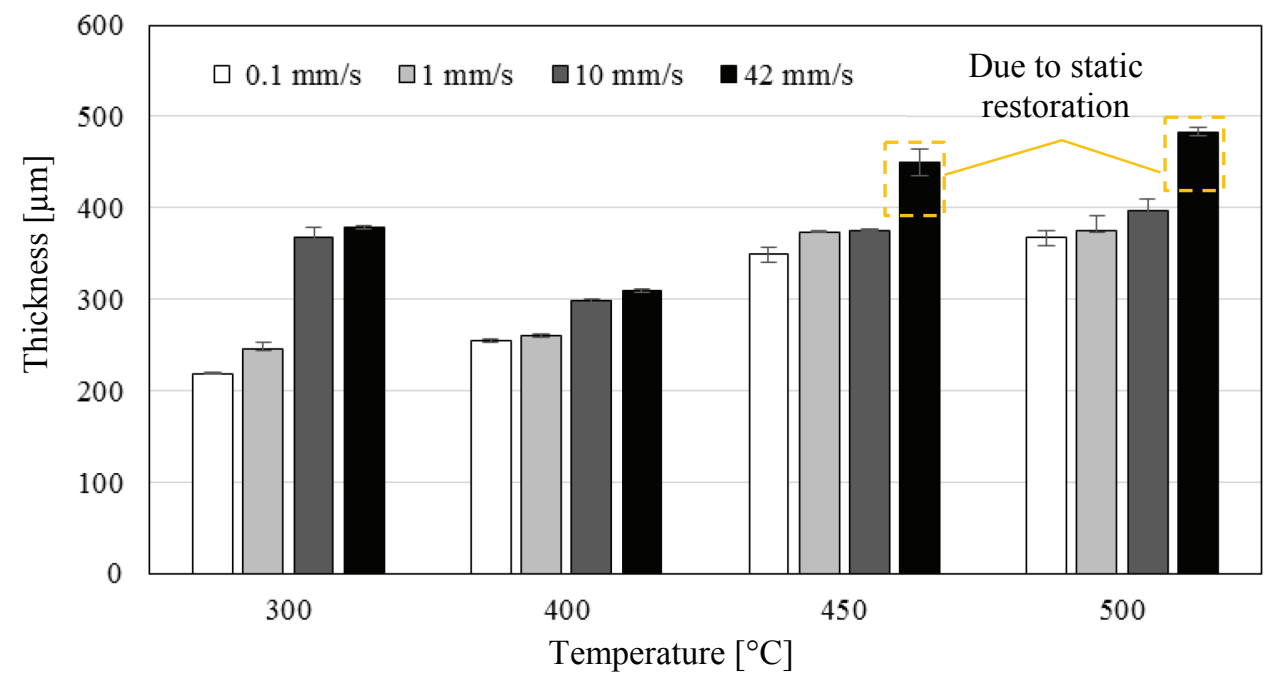

FIGURE 4. Thickness of the high shear deformation zone of aluminum alloy EN AW-6060 after sticking friction

\section{CONCLUSIONS}

Sticking friction experiments were carried out to study the sub-surface deformation of aluminium alloy EN AW6060 under different temperatures and sliding speeds. Metallographic analysis of the friction boundary layer revealed a severe deformation below the friction surface, which was distinguished to the adjacent slightly deformed dendritic grains. Moreover, the experimental results allowed to quantify the thickness evolution of the high shear deformation zone. The thickness variation was more influenced by the sliding speed at $300{ }^{\circ} \mathrm{C}$ than at higher temperatures. Increasing the sliding speed from $0.1 \mathrm{~mm} / \mathrm{s}$ to $42 \mathrm{~mm} / \mathrm{s}$ the thickness grew up around $70 \%$ at $300{ }^{\circ} \mathrm{C}$ while $20 \%$, $28 \%$ and $30 \%$ was measured at $400{ }^{\circ} \mathrm{C}, 450{ }^{\circ} \mathrm{C}$ and $500{ }^{\circ} \mathrm{C}$ respectively. This effect is related to the greater influence of strain hardening at $300^{\circ} \mathrm{C}$ and the more efficient dynamic recovery at higher temperatures. Additionally, different grain structures could be detected in the high deformation zone by means of LOM. In this sense, fibrous structure was observed at $300{ }^{\circ} \mathrm{C}$ and $400{ }^{\circ} \mathrm{C}$. Moreover, small equiaxed grains were detected at $450{ }^{\circ} \mathrm{C}$ possibly generated by means of geometric dynamic recrystallization $\mathrm{gDRX}$. Additionally coarse grains surrounded by equiaxed grains were generated at $450{ }^{\circ} \mathrm{C}$ and a high sliding speed $(10 \mathrm{~mm} / \mathrm{s}, 42 \mathrm{~mm} / \mathrm{s})$ which is evidence of abnormal grain growth. On the other hand, coarse grains at $500{ }^{\circ} \mathrm{C}$ and high speed $(10 \mathrm{~mm} / \mathrm{s}, 42 \mathrm{~mm} / \mathrm{s})$ suggested that enough stored strain energy was generated to produce a normal static recrystallization, grain growth or a combination of both processes. 


\section{REFERENCES}

1. N. Parson, S. Barker, A. Shalanski and C. Jowett. "Control of Grain Structure in Al-Mg-Si Extrusions". Proc. of the Eighth Int. Aluminium Extrusion Tech. Seminar, Orlando, Florida, USA (2004) Vol. 1, pp. 11-21.

2. E. Sweet et al. "Effects of extrusion parameters on coarse grain surface layer in 6xxx series extrusions". Proc. of the 8th Int. Aluminum Extrusion Tech. Seminar, Orlando, Florida, USA (2004) Vol. 1 pp 115-126.

3. W. Geertruyden and W. Misiolek. "Analysis of Peripheral Coarse Grain Recrystallization in 6XXX Aluminium Alloy Extrusion". Proc. of the Eighth Int. Aluminium Extrusion Tech. Seminar, Orlando, Florida, USA (2004) Vol. 1, pp. 107-113.

4. W. Geertruyden, H. Browne, W. Misiolek and P. Wang. "Evolution of surface recrystallization during indirect extrusion of 6xxx aluminum alloys". Metall Mater Trans A. (2004) Vol. 36A, pp. 1049-1056.

5. A. Ockewitz, D. Sun, F. Andrieux and S. Mueller. "Simulation of Hot Extrusion of an Aluminium Alloy with Modeling of Microstructure". KEM. (2012) Vol. 491, pp. 257-264.

6. V. Sanabria, S. Mueller and W. Reimers. "A new high speed friction test for extrusion processes". KEM. (2014) Vol. 585, pp. 33-39.

7. V. Sanabria, S. Mueller and W. Reimers. "Friction modelling in long bearing channels during multi-hole extrusion of aluminium alloy". Materials Today: Proceedings 2 (2015) 4820-4828.

8. V. Sanabria, S. Mueller and W. Reimers. "Microstructure evolution of friction boundary layer during extrusion of AA 6060". Procedia Engineering (2014) Vol. 81, pp. 586-591.

9. S. Gourdet and H. McQueen. "High temperature deformation of 6060 aluminum alloy". Light Metal 99, 326, pp 575-582.

10. A. Gholinia, F. Humphreys and P. Prangnell. "Production of ultra-fine grain microstructure in Al-Mg alloys by conventional rolling". Acta Materialia 50 (2002) 4461-4476.

11. W. Geertruyden, W. Misiolek and P. Wang. "Grain structure evolution in a 6061 aluminium alloy during hot torsion”. Materials Science and Engineering A419 (2006) pp.105-114.

12. F.J. Humphreys and M. Hatherly. Recrystallization and Related Annealing Phenomena. Second Edition, Oxford, 2004.

13. T. Pettersen, B. Holmedal and E. Nes. "Microstructure development during hot deformation of aluminium to large strains". Metall Mater Trans A. Vol. 34A, (2003) pp. 2737-2744.

14. H.J. McQueen. "Development of dynamic recrystallization theory". Mater Sci Eng A. 387-389 (2004) 203-208.

15. H. McQueen. "Mechanisms in creep and hot working to high strain; microstructural evidence: inconsistencies. Part I: substructure evolution; grain interactions". Metall. Sci. technol. (2010) 28, 12-21.

16. H. McQueen and W. Tegart. "The deformation of metals at high temperatures". Scientific American (1975) Vol. 232, issue 4. pp. 116-125.

17. M. Huh et al. "Effects of primary recrystallization texture on abnormal grain growth in an aluminum alloy". Scripta Materialia 57 (2007) 325-327.

18. K. Iharam and T. Shikama. "Effect of extrusion temperature on recrystallized grain structures of extruded AlMg-Si alloys". Proceedings of the 12th International Conference on Aluminium Alloys. (2010) 2012-2017. 